\title{
Decisional conflict and vaccine uptake: cross-sectional study of 2012/2013 influenza season in Croatia
}

Ivančica Pavličević ${ }^{1}$, Slavica Škrabić ${ }^{1}$, Mario Malički ${ }^{2}$, Ana Hrvojka Merćep ${ }^{1}$, Matko Marušić ${ }^{2}$, Ana Marušić

${ }^{1}$ Family Practice Office, Split, Croatia

${ }^{2}$ School of Medicine, University of Split, Split, Croatia

Submitted: 4 February 2014

Accepted: 23 April 2014

Arch Med Sci 2015; 11, 4: 788-795

DOI: 10.5114/aoms.2015.53299

Copyright $\odot 2015$ Termedia \& Banach

\author{
Corresponding author: \\ Mario Malički MD \\ School of Medicine \\ University of Split \\ Šoltanska 2 \\ 21000 Split, Croatia \\ Phone: +38 5915840149 \\ E-mail: \\ mario.malicki@mefst.hr
}

\begin{abstract}
Introduction: As scientific, media and individual opinions on the need for seasonal influenza vaccination differ, we explored patients' decisional conflict and perceived physician and social support when making a vaccination choice.

Material and methods: We conducted a survey of patients with previous vaccination experience in a single family medicine office in Split, Croatia. The questionnaire included the Decisional Conflict Scale (DCS), perceived social support, and attitudes and knowledge concerning vaccination.

Results: Out of 203 (86\%) adult patients with previous vaccination experience, 182 (40.4\%) opted to vaccinate in the current season, 98 (48.3\%) refused, and $22(11.3 \%)$ were undecided. The median decisional conflict score was highest among those undecided (43.8 out of the maximum 100, interquartile range (IQR) 33.2-52.3), lowest among those opting to vaccinate (17.2, IQR 9.4-26.6), and intermediate among those who refused vaccination (25.0, IQR 17.2-39.1) ( $p<0.001$, Kruskal-Wallis test and post-hoc Mann-Whitney $U$ tests). The most common self-reported reasons for vaccination were previous vaccination experience $(n=85,42 \%)$ and media information $(n=62,30 \%)$. Those who refused vaccination felt less satisfied with the support they received from their family physician than those who decided to vaccinate (median 6.5 (IQR 0-9) vs. 9 (IQR 5-10) on a scale from 0 to 10 ), respectively; $p=0.001$, Mann-Whitney $U$ test).

Conclusions: Higher decisional conflict of patients who refuse influenza vaccination and those undecided, alongside their perceived low support of the family physician in making that choice, emphasize the importance family doctors play in advising and helping patients make informed decisions about seasonal influenza vaccination.
\end{abstract}

Key words: conflict (psychology), decision making, physicians, family.

\section{Introduction}

A recent Cochrane systematic review showed that when the influenza vaccine completely matches the circulating viral configuration, 33 healthy adults need to be vaccinated to avoid 1 set of influenza symptoms, and 100 when that match is only partial [1]. Other systematic reviews of efficacy of vaccination for healthy children and the elderly found no evidence to support wide public vaccinations [2,3] and some evidence to support vaccination for patients suffering from chronic obstructive pulmonary disease or for immunosuppressed adults with cancer $[4,5]$. These find- 
ings, together with an increase in public mistrust towards vaccinations [6], especially following the H1N1 outbreak, have resulted in a recent decrease in public influenza vaccination rates [7]. Additionally, conflicting information available in the media and on the Internet [8,9], different public and healthcare vaccination polices and reimbursement coverage among countries [10-13], incomplete reporting of side effects and yearly deaths caused by influenza [14], as well as the lack of reporting of numbers needed to vaccinate for each country or region $[15,16]$, makes it difficult for individuals to decide whether or not to vaccinate.

In Croatia, influenza vaccination is recommended for everyone above 65 years of age, as well as for all health care professionals, yet the number of lay persons and healthcare workers getting vaccinated has been decreasing since 2009 [17, 18]. In order to determine whether the level of decisional conflict and perceived physician support differ among those who accept or refuse vaccination against the seasonal influenza, we conducted a survey on patients registered at a single family physician's office in Split, Croatia.

\section{Material and methods}

\section{Participants}

Participants were recruited from a single primary health care (family medicine) office in Split, Croatia, with a catchment population of 1774 during the 2012/2013 influenza season. Eligible survey participants were adults who were at least once in their lifetime vaccinated against influenza.

As the sample included 23 married couples (both spouses separately participated in the study during their individual visit to the family medicine physician), we tested the dependency of their responses by comparing spouses' decisions to get vaccinated and their DCS scores: in 6 of 23 couples (26\%) spouses had made different choices to get vaccinated, and in 3 out of 23 couples (13\%) both spouses had the same decisional conflict score. As these results could be indicative of dependence, we conducted a randomized pairwise exclusion of one of the spouses. However, the results with and without the exclusion did not yield significant differences (data not shown), and the spouses were treated as independent participants.

\section{Questionnaires}

At the doctor's office, each participant completed a questionnaire that consisted of three parts: demographic data, questions on perceived vaccination support and vaccination risks and benefits. The questionnaire was based on the Ottawa Personal Decision Guide and Influenza Decision Aid [19] (Appendix 1), as well as O'Connor's Decision- al Conflict Scale (DCS) [20]. The DCS consists of 16 items rated in a 5-point Likert-type response format, and measures individual's uncertainty toward a course of action. The DCS consists of five subscales: uncertainty, informed, values clarity, support and effective decision. It has been used in a variety of settings and decision supporting interventions [21]. The DCS is freely available for researchers from the following webpage: http:// decisionaid.ohri.ca/docs/develop/User_Manuals/ UM_Decisional_Conflict.pdf. The scores on the total scale and subscales are calculated as a sum of items, divided by the number of items and multiplied by 25 , allowing for a score range from zero (no decisional conflict) to 100 points (extreme decisional conflict) [20]. The English version of the DCS had been translated into Croatian by the authors and then back translated by an independent language expert to confirm its validity. The survey was piloted for content and face validity among a convenience sample of 5 patients. Cronbach's $\alpha$ of the DCS scale for our sample was 0.904 .

\section{Statistical analysis}

Data are presented as frequencies for categorical variables and median with interquartile range (IQR) or $95 \%$ confidence interval. Statistical differences among the groups were analyzed using MedCalc v.12.5 (MedCalc, Ostend, Belgium). Two-sided significance testing was used for the $\chi^{2}$ test and Kruskal-Wallis test with post-hoc Mann-Whitney $U$ tests.

\section{Ethical approval}

The study was approved by the ethical review board of the University of Split, Croatia (no. 00308/13-03/0003) and all participants consented to take part.

\section{Results}

The final study sample included 203 patients ( $86 \%$ of 235 adult patients with previous vaccination experience; 104 men and 99 women). In the 2012/2013 flu season, 82 of them (40.4\%) decided to get vaccinated, 98 (48.3\%) decided against it, and $23(11.3 \%)$ were undecided the time of the survey. There were no differences between the three groups in their sociodemographic characteristics (Table I), except in their age, with those who decided not to get vaccinated being younger that those belonging to the other two groups $(H=15.1941, \mathrm{~d} f=2, p<0.001)$. Also, those who decided to get vaccinated had been more often vaccinated in the past than those who decided against vaccination.

All three groups differed in their total DCS score, with those undecided about the vaccina- 
Table I. Characteristics of patients $(n=203)$ from a family medicine office in Split, Croatia, according to their decision to have their yearly influenza vaccination

\begin{tabular}{|c|c|c|c|c|}
\hline \multirow[t]{2}{*}{ Characteristics } & \multicolumn{3}{|c|}{ No. (\%) of subjects with respect to their decision to vaccinate } & \multirow[t]{2}{*}{ Value of $p^{*}$} \\
\hline & Yes $(n=82)$ & No $(n=98)$ & Still undecided $(n=23)$ & \\
\hline \multicolumn{4}{|l|}{ Gender: } & 0.690 \\
\hline Male & $45(55)$ & $48(49)$ & $11(48)$ & \\
\hline Female & $37(45)$ & $50(51)$ & $12(52)$ & \\
\hline Age, median (IQR) [years] & $75(72-78)$ & $70(63-76)$ & $75(67-79)$ & $<0.001^{\dagger}$ \\
\hline \multicolumn{4}{|l|}{ Marital status: } & 0.558 \\
\hline Married & $57(69)$ & $76(78)$ & $16(69)$ & \\
\hline Divorced & $3(4)$ & $4(4)$ & $0(0)$ & \\
\hline Single & $3(4)$ & $2(2)$ & $2(9)$ & \\
\hline Widowed & $19(23)$ & $16(16)$ & $5(22)$ & \\
\hline No. of children, median (IQR) & $3(2-3)$ & $3(2-3)$ & $3(2-3)$ & $0.585^{\dagger}$ \\
\hline \multicolumn{4}{|l|}{ Employment status: } & 0.060 \\
\hline Employed & $3(4)$ & $12(12)$ & $2(8)$ & \\
\hline Unemployed & $0(0)$ & $4(4)$ & $0(0)$ & \\
\hline Retired & $79(96)$ & $82(84)$ & $21(92)$ & \\
\hline \multicolumn{4}{|l|}{ Education: } & 0.321 \\
\hline Elementary school & $14(17)$ & $8(8)$ & $2(9)$ & \\
\hline High school & $44(54)$ & $55(56)$ & $11(48)$ & \\
\hline Specialist degree & $9(11)$ & $13(13)$ & $2(9)$ & \\
\hline University degree & $13(18)$ & $21(22)$ & $8(34)$ & \\
\hline Missing data & $2(2)$ & $1(1)$ & $0(0)$ & \\
\hline \multicolumn{4}{|l|}{ Income (in HRK‡): } & 0.909 \\
\hline$\leq 2000$ & $13(16)$ & $17(17)$ & $2(9)$ & \\
\hline$>2000$ to $\leq 3000$ & $30(37)$ & $29(30)$ & $8(35)$ & \\
\hline$>3000$ to $\leq 4000$ & $21(26)$ & $26(27)$ & $8(35)$ & \\
\hline$>4000$ to $\leq 5000$ & $6(7)$ & $8(8)$ & $1(4)$ & \\
\hline$>5000$ & $10(12)$ & $13(13)$ & $3(12)$ & \\
\hline Missing data & $2(2)$ & $5(5)$ & $1(4)$ & \\
\hline \multicolumn{4}{|c|}{ No. of previous influenza infections: } & 0.712 \\
\hline 0 & $11(13)$ & $22(23)$ & $6(26)$ & \\
\hline 1 & $16(20)$ & $17(17)$ & $5(22)$ & \\
\hline $2-5$ & $43(52)$ & $44(45)$ & $9(39)$ & \\
\hline$\geq 6$ & $12(15)$ & $15(15)$ & $3(13)$ & \\
\hline \multicolumn{4}{|c|}{ No. of previous influenza vaccinations: } & $<0.001$ \\
\hline 1 & $1(1)$ & $31(32)$ & $2(9)$ & \\
\hline $2-5$ & $16(20)$ & $38(39)$ & $8(35)$ & \\
\hline$\geq 6$ & $65(79)$ & $29(29)$ & $13(56)$ & \\
\hline
\end{tabular}

${ }^{*} \chi^{2}$ test, ${ }^{\dagger}$ Kruskal-Wallis test, ${ }^{\ddagger} 7.5$ HRK $=1 €$. 
tion having the greatest decisional conflict, followed by those who decided against vaccination, and finally those deciding to vaccinate (Table II). The greatest influence on the total score were the scores of the Effective decision and Informed subscale, where the same differences were observed among the groups (Table II). Whereas there was no difference among the groups in the Uncertainty subscale score, the scores for Values clarity and Support subscales were lower in those who decided to vaccinate than in the other two groups, between whom there was no difference (Table II).

The most frequent reason the participants from all groups reported as important in making their decision whether or not to vaccinate was their previous experience with vaccination $(n=85$, $42 \%)$, followed by the information from the media and the Internet $(n=62,31 \%)$ (Table III). However, a higher proportion of those who decided to get vaccinated based their decision on their previous vaccination experience $\left(\chi^{2}=5.041, \mathrm{~d} f=1\right.$, $p=0.025)$, whereas more of those who decided against vaccination or were undecided based their decision on the media and internet $\left(\chi^{2}=31.477\right.$, $\mathrm{d} f=2, p<0.001)$. Only $12(6 \%)$ respondents listed advice from the family physician as their main reason for vaccination (Table III).

The majority of participants $(n=193,95 \%)$ reported experiencing no pressure from others because of their decision. In families of those who were undecided or decided against vaccination there were more family members who decided against vaccination (Table III). More respondents who decided to vaccinate than those in the other two groups felt that they knew the most important benefits and risks of vaccination (Table III). Participants who decided to vaccinate were most confident that their choice was the best for them, and reported higher clarity about benefits and risks associated with the vaccination (Table III).

The three groups did not differ in the self-perceived support they had or in the importance of the role they wished to have in making a decision about vaccination (Table IV). The majority (65\%) of those who made their decision (either for or against vaccination) felt that decision-making should be solely theirs and that it should be made after they heard the opinions of others. On the other hand, $48 \%$ of those still undecided about vaccination reported that the decision-making process should be shared (Table IV). In their assessment about the need for support for their decision, the three groups differed only in the support they wanted to receive from their family physician, with those who decided against vaccination reporting less need for the family physician's support (Table IV). The three groups did not differ in the satisfaction with the support they received from family, friends or specialists, but those who decided against vaccination felt less satisfied with the support they received from their family physician than those who decided to vaccinate (Table IV).

\section{Discussion}

Our study showed that the decision regarding seasonal influenza vaccination of patients in the setting of primary health care practice was associated with different strengths of their conviction about that decision. The greatest decisional conflict was present in undecided patients and the greatest conviction in those who decided to vaccinate. Whereas the highest level of decisional conflict in the undecided group seems self-evident, higher conviction of subjects who decided to vaccinate than of those who refused vaccination is a novel finding. As our

Table II. Decisional Conflict Test scores of 203 patients from a family medicine office according to their decision to have their yearly influenza vaccination

\begin{tabular}{|c|c|c|c|c|}
\hline \multirow[t]{2}{*}{ Score on scale/subscale* } & \multicolumn{3}{|c|}{$\begin{array}{l}\text { No. of points according to influenza vaccination decision } \\
\text { (median, interquartile range) }\end{array}$} & \multirow[t]{2}{*}{ Value of $p^{\dagger}$} \\
\hline & Yes $(n=82)$ & No $(n=98)$ & Undecided $(n=23)$ & \\
\hline Total score* & $17.2(9.4-26.6)$ & $25.0(17.2-39.1)$ & $43.8(33.2-52.3)$ & $<0.001^{\ddagger}$ \\
\hline Uncertainty subscore & $16.7(8.3-33.3)$ & $25.0(16.7-41.7)$ & $25.0(16.7-47.9)$ & 0.3741 \\
\hline Informed subscore & $8.3(0.0-25.0)$ & $25.0(8.3-41.7)$ & $58.3(41.7-72.9)$ & $<0.001^{\ddagger}$ \\
\hline Values clarity subscore & $25.0(16.7-33.3)$ & $33.3(25.0-41.6)$ & $41.7(27.1-47.9)$ & $<0.001^{\S}$ \\
\hline Support subscore & $25.0(0.0-33.3)$ & $33.3(25.0-50.0)$ & $41.7(33.3-50.0)$ & $<0.001^{\S}$ \\
\hline Effective decision subscore & $6.3(0.0-18.8)$ & $18.8(6.3-31.3)$ & $43.8(31.3-50.0)$ & $<0.001^{\ddagger}$ \\
\hline
\end{tabular}

*Score range for the full scale and subscales: from 0 (no decisional conflict, feels extremely certain about best choice, feels extremely informed, feels extremely clear about personal values for benefits and risk/side effects, feels extremely supported in decision-making, good decision, respectively) to 100 (extremely high decisional conflict, feels extremely uncertain about best choice, feels extremely uninformed, feels extremely unclear about personal values, feels extremely unsupported in decision-making, bad decision, respectively). ${ }^{\top} K$ ruskal-Wallis test, "Statistically significant difference among all groups (post-hoc Mann-Whitney U tests), `Statistically significant difference between the group deciding to receive vaccination vs. other two groups (post-hoc Mann-Whitney U test). 
Table III. Reported reasons for vaccination choice, perceived pressure and knowledge of seasonal influenza vaccination

\begin{tabular}{|c|c|c|c|c|}
\hline \multirow[t]{2}{*}{ Characteristic } & \multicolumn{3}{|c|}{ No. (\%) of subjects with respect to their decision to vaccinate } & \multirow[t]{2}{*}{ Value of $p^{*}$} \\
\hline & Yes $(n=82)$ & No $(n=98)$ & Undecided $(n=23)$ & \\
\hline \multicolumn{5}{|l|}{ Reason for the decision: } \\
\hline $\begin{array}{l}\text { Advice from family } \\
\text { medicine physician }\end{array}$ & $9(11)$ & $3(3)$ & $0(0)$ & $<0.001$ \\
\hline $\begin{array}{l}\text { The family was for } \\
\text { subject's vaccination }\end{array}$ & $1(1)$ & $1(1)$ & $1(4)$ & \\
\hline Advice from friends & $0(0)$ & $0(0)$ & $0(0)$ & \\
\hline $\begin{array}{l}\text { Own decision on the } \\
\text { basis of media/Internet } \\
\text { information }\end{array}$ & $7(9)$ & $44(45)$ & $11(48)$ & \\
\hline $\begin{array}{l}\text { Experience from previous } \\
\text { vaccination }\end{array}$ & $43(52)$ & $34(35)$ & $8(35)$ & \\
\hline Other & $9(11)$ & $13(13)$ & $3(13)$ & \\
\hline Multiple reasons & $13(16)$ & $3(3)$ & $0(0)$ & \\
\hline \multicolumn{5}{|c|}{ Decision made without pressure from others: } \\
\hline Yes & $80(98)$ & $90(92)$ & $23(100)$ & 0.107 \\
\hline No & $2(2)$ & $8(8)$ & 0 & \\
\hline \multicolumn{5}{|c|}{ Family members plan to vaccinate: } \\
\hline Yes & $32(39)$ & $8(8)$ & $1(4)$ & $<0.001$ \\
\hline No & $50(61)$ & $90(92)$ & $22(96)$ & \\
\hline \multicolumn{5}{|c|}{ Knowledge of most important risks and benefits of vaccination: } \\
\hline Yes & $71(87)$ & $64(65)$ & $14(61)$ & 0.002 \\
\hline No & $11(13)$ & $34(35)$ & $9(39)$ & \\
\hline $\begin{array}{l}\text { Level of confidence that the } \\
\text { decision was the best for me, } \\
\text { median (IQR) }\end{array}$ & $10(8-10)^{\S}$ & $8(5-10)$ & $6(4-7)$ & $<0.001^{\dagger}$ \\
\hline $\begin{array}{l}\text { Level of clarity about benefits } \\
\text { and risks, median }(\mathrm{IQR})^{\ddagger}\end{array}$ & $7(6-9)^{\S}$ & $6(5-7)$ & $6(5-8)$ & $<0.001^{\dagger}$ \\
\hline
\end{tabular}

sample included only those who were previously vaccinated at least once in their lives, it is possible that previously unvaccinated patients who refuse vaccination would have the same level of conviction against vaccination as those who accepted vaccination after a previous vaccination experience. However, studies of decisional conflict in other situations showed that previous experience does not influence the decision on a health issue [22]. A possible explanation for the difference in decisional conflict between patients who made a choice for or against influenza vaccination may be related to the lack of universal agreement on influenza vaccination and the lack of an open dialogue with the public $[11,15]$. Furthermore, as those who decided against vaccination in our study were less satisfied with the support of family physicians and reported lesser need of that support, it is possible that the impact of incongruousness regarding influenza vaccination could have a larger impact on the overall trust between the physician and the patient.

Respondents in our study who were still undecided about influenza vaccination reported the same level of influence of media and Internet information on their choice as those who decided against vaccination, but a higher need for support of a family physician and for shared decision-making and information on actual risks and benefits. This finding emphasizes the importance of timing that the consultation or written communication from family medicine physicians can play in the decision-making process. Several studies have shown that age was the most important predictor of patient preference for participation in decision-making, with younger patients desiring greater involvement $[23,24]$. There is also evi- 
Table IV. Support that the patients had in making their decision about seasonal influenza vaccination

\begin{tabular}{|c|c|c|c|c|}
\hline \multirow[t]{2}{*}{ Characteristic } & \multicolumn{3}{|c|}{ No. (\%) of subjects with respect to their decision to vaccinate } & \multirow[t]{2}{*}{ Value of $p^{*}$} \\
\hline & Yes $(n=82)$ & No $(n=98)$ & Undecided $(n=23)$ & \\
\hline \multicolumn{4}{|l|}{ Had enough support: } & \multirow[t]{3}{*}{0.3714} \\
\hline Yes & $34(41)$ & $48(49)$ & $8(35)$ & \\
\hline No & $48(59)$ & $50(51)$ & $15(65)$ & \\
\hline \multicolumn{4}{|c|}{ Role an individual would like to have in making the decision: } & \multirow[t]{4}{*}{0.7014} \\
\hline Large & $63(77)$ & $81(83)$ & $18(78)$ & \\
\hline Small & $17(21)$ & $14(14)$ & $5(22)$ & \\
\hline None & $2(2)$ & $3(3)$ & $0(0)$ & \\
\hline \multicolumn{4}{|c|}{ Type of role an individual would like to have in making the decision: } & \multirow[t]{4}{*}{0.004} \\
\hline Shared decision & $19(23)$ & $35(36)$ & $11(48)$ & \\
\hline $\begin{array}{l}\text { Decision after learning of } \\
\text { opinions of others }\end{array}$ & $56(68)$ & $61(62)$ & $8(35)$ & \\
\hline Delegating decision to others & $7(9)$ & $2(2)$ & $4(17)$ & \\
\hline \multicolumn{4}{|l|}{ In need of support from: } & \multirow[t]{8}{*}{0.0254} \\
\hline Family & $18(22)$ & $23(24)$ & $5(22)$ & \\
\hline Media & $4(6)$ & $5(5)$ & 0 & \\
\hline Family medicine physician & $29(35)$ & $14(14)$ & $12(52)$ & \\
\hline Specialist & $2(2)$ & $5(5)$ & $1(4)$ & \\
\hline Friends & 0 & $3(3)$ & 0 & \\
\hline Scientific literature & $2(2)$ & $2(2)$ & 0 & \\
\hline No need for support of others & $27(33)$ & $46(47)$ & $5(22)$ & \\
\hline \multicolumn{5}{|c|}{ Satisfied with support of (median, interquartile range) $)^{\ddagger}$ : } \\
\hline Family & $10(5-10)$ & $8(5-10)$ & $9(5-10)$ & $0.1029^{\dagger}$ \\
\hline Family medicine physician & $9(5-10)$ & $6.5(0-9)^{\S}$ & $7(4-9)$ & $<0.001^{\dagger}$ \\
\hline Specialist & $0(0-5)$ & $0(0-5)$ & $0(0-5)$ & $0.6653^{\dagger}$ \\
\hline Friends & $0(0-6)$ & $2(0-6)$ & $4(0-6)$ & $0.3146^{\dagger}$ \\
\hline
\end{tabular}

${ }^{*} \chi^{2}$ test, ${ }^{\dagger}$ Kruskal-Wallis test, ${ }^{\ddagger}$ Indicated on a numerical scale from 0 to $10,{ }^{5} p=0.001 \mathrm{vs}$. those who decided to vaccinate, post-hoc MannWhitney $U$ test.

dence that better educated people prefer greater involvement in decision-making than less educated ones [25]. In our study, the level of education of the participants did not influence their decision on vaccination, but those who decided not to get vaccinated were younger than those belonging to the other two groups. It is also possible that participants' personality traits, especially anxiety, depression or procrastination, had an impact on their vaccination choice or indecisiveness [26, 27]. Further research should aim to evaluate these traits and their influence on influenza and other vaccination rates.

Finally, our study also showed that a large majority of those who remained true to their previous decision and decided to vaccinate again, as well as those who refused vaccination, based their choice on their personal experience with the previous vaccination, while only a dozen (6\%) based it on advice from a family physician. Although our study was not designed to investigate the reasons for this phenomenon, the fact that on average only 13 minor adverse reactions to the vaccination have been reported for the last 5 influenza seasons in Croatia [18] (and none from the family physician's office in this study) indicates that the public still thinks that the vaccination is designed to completely protect them from influenza, and not "just" to decrease its severity. Furthermore, these findings indicate the need for periodic influenza discussions with patients, even when they are making the recommended choice. 
The limitations of our study are its sample size, especially the low number of those still undecided about vaccination, and the high age of the participants. Nevertheless, the response rate of $86 \%$ made this sample representative for the population of adult and elderly patients in a typical family medicine office. The fact that the study was conducted in a single family medicine office from a large city also decreases the generalizability of our findings. However, as the vaccination rate in the family medicine office was similar to that reported for the whole country [18] and individuals aged $\geq 65$ years are in most countries the group targeted for influenza vaccination [10], the results of the study may be representative at least for the city population in Croatia and countries with similar socioeconomic characteristics and health care systems.

In conclusion, our findings demonstrate that patients deciding to get vaccinated against seasonal influenza are faced with a conflicting decision which could be alleviated by the support and advice from their family physician. Patients rely not only on clinical evidence, professional guidelines and media recommendations, but also on experiences they themselves had with the previous seasonal vaccination, and these issues should be taken into consideration in planning interventions aimed at increasing vaccination rates and in developing patient decision aids regarding influenza vaccination.

\section{Conflict of interest}

The authors declare no conflict of interest.

\section{References}

1. Jefferson T, Di Pietrantonj C, Rivetti A, Bawazeer GA, Al-Ansary LA, Ferroni E. Vaccines for preventing influenza in healthy adults. Cochrane Database Syst Rev 2010; 7: CD001269.

2. Jefferson T, Di Pietrantonj C, Al-Ansary LA, Ferroni E, Thorning S, Thomas RE. Vaccines for preventing influenza in the elderly. Cochrane Database Syst Rev 2010: 2: CD004876.

3. Jefferson T, Rivetti A, Di Pietrantonj C, Demicheli V, Ferroni E. Vaccines for preventing influenza in healthy children. Cochrane Database Syst Rev 2012; 8: CD004879.

4. Poole PJ, Chacko E, Wood-Baker RW, Cates CJ. Influenza vaccine for patients with chronic obstructive pulmonary disease. Cochrane Database Syst Rev 2006; 1: CD002733.

5. Eliakim-Raz N, Vinograd I, Zalmanovici Trestioreanu A, Leibovici L, Paul M. Influenza vaccines in immunosuppressed adults with cancer. Cochrane Database Syst Rev 2013; 10: CD008983.

6. Larson HJ, Cooper LZ, Eskola J, Katz SL, Ratzan S. Addressing the vaccine confidence gap. Lancet 2011; 378: 526-35.

7. Bish A, Yardley L, Nicoll A, Michie S. Factors associated with uptake of vaccination against pandemic influenza: a systematic review. Vaccine 2011; 29: 6472-84.
8. Covolo L, Mascaretti S, Caruana A, Orizio G, Caimi L, Gelatti U. How has the flu virus infected the Web? 2010 influenza and vaccine information available on the Internet. BMC Public Health 2013; 13: 83.

9. Ofstead CL, Sherman BW, Wetzler HP, et al. Effectiveness of worksite interventions to increase influenza vaccination rates among employees and families. J Occup Environ Med 2013; 55: 156-63.

10. Palache A. Seasonal influenza vaccine provision in 157 countries (2004-2009) and the potential influence of national public health policies. Vaccine 2011; 29: 9459-66.

11. System R. Seasonal influenza vaccine policies, recommendations and use in the World Health Organization's Western Pacific Region. Western Pac Surveill Response J 2013; 4: 51-9.

12. Galanakis E, D'Ancona F, Jansen A, Lopalco PL. The issue of mandatory vaccination for healthcare workers in $\mathrm{Eu}$ rope. Expert Rev Vaccines 2014; 13: 277-83.

13. Abdollahiasl A, Nikfar S, Kebriaeezadeh A, Dinarvand R, Abdollahi M. A model for developing a decision support system to simulate national drug policy indicators. Arch Med Sci 2011; 7: 744-6.

14. World Health Organization. Interim Epidemiological Surveillance Standards for Influenza. WHO, Geneva 2012.

15. Public Health Development. Annual influenza vaccine effectiveness meeting 2013. European Centre for Disease Prevention and Control (ECDC), 2013.

16. European Centre for Disease Prevention and Control. Annual epidemiological report 2013: Reporting on 2011 surveillance data and 2012 epidemic intelligence data. Stockholm: ECDC, 2013.

17. Civljak R, Papic N, Stamenic V, Kalenic S, Kuzman I, Car J. Influenza and hepatitis B vaccination coverage among healthcare workers in Croatian hospitals: a series of cross-sectional surveys, 2006-2011. BMC Infect Dis 2013; 13: 520.

18. Department for Epidemiology. Annual Report. Croatian National Institute of Public Health, 2013.

19. The Patient Decision Aids Research Group. Ottawa Patient Decision Aids. Ottawa 2013; Available from: http://decisionaid.ohri.ca/decaids.html.

20. O'Connor AM. Validation of a decisional conflict scale. Med Decis Making 1995; 15: 25-30.

21. Stacey D, Bennett CL, Barry MJ, et al. Decision aids for people facing health treatment or screening decisions. Cochrane Database Syst Rev 2011; 10: CD001431.

22. Sanderson S, Linderman M, Kasarskis A, et al. Informed decision-making among students analyzing their personal genomes on a whole genome sequencing course: a longitudinal cohort study. Genome Med 2013; 5: 113.

23. Cassileth BR, Zupkis RV, Suttonsmith K, March V. Information and participation preferences among cancer-patients. Ann Intern Med 1980; 92: 832-6.

24. Strull WM, Lo B, Charles G. Do patients want to participate in medical decision-making. JAMA 1984; 252: 2990-4.

25. Deber RB. Physicians in health care management: 8 . The patient-physician partnership: decision making, problem solving and the desire to participate. CMAJ 1994; 151: 423-7.

26. Umeh K, Omari-Asor L. Emotional vulnerability and coping styles for resolving decisional conflict. J Psychol 2011; 145: 297-312.

27. Steel P. The nature of procrastination: a meta-analytic and theoretical review of quintessential self-regulatory failure. Psychol Bull 2007; 133: 65-94. 


\section{Appendix 1. Questionnaire}

Patient's registration no.: ....

Decision regarding vaccination: $\square$ Yes $\square$ No $\square$ Still undecided

Age: ___ Gender: ___ Employment status:

Income: HRK/month.

Marital status: $\square$ Married $\square$ Divorced $\square$ Unmarried $\square$ Widowed

Educational level:

Number of children:

How many times in your life have you had the flu (number)?

How many times in your life have you been vaccinated against the flu?

Which chronic illnesses do you have? $\square$ Diabetes $\square$ Hypertension $\square \overline{\text { Chronic bronchitis }}$

$\square$ Chronic kidney illness $\square$ Other (please list):

$\square$ I do not have a chronic illness.

Has someone from your family been vaccinated against the flu this year? $\square$ Yes $\square$ No

If yes, who?

Please explain the reason behind your vaccination decision:

$\square$ I was advised so by my family medicine doctor.

$\square$ I was advised so by my family.

$\square$ I was advised so by my friends.

$\square$ I decided by myself based on the information available in the literature and media.

$\square$ I decided based on my previous experience with vaccination.

$\square$ Other reason (please describe):

Do you have enough support and advice from others to make a decision about the vaccination? $\square$ Yes $\square$ No Are you making your decision without pressure from others? $\square$ Yes $\square$ No

How satisfied are you with your family's support regarding your decision about vaccination?

$\begin{array}{ccccccccccc}0 & 1 & 2 & 3 & 4 & 5 & 6 & 7 & 8 & 9 & \begin{array}{c}10 \\ \text { Completely }\end{array} \\ \text { Not at all } & & & & & & & & & \end{array}$

How satisfied are you with your family medicine doctor's support regarding your decision about vaccination?

$$
\begin{array}{cccccccccccc}
0 & 1 & 2 & 3 & 4 & 5 & 6 & 7 & 8 & 9 & 10 \\
\text { Not at all } & & & & & & & & & & \text { Completely }
\end{array}
$$

How satisfied are you with the support of some other doctor (e.g. a specialist) regarding your decision about vaccination?

$\begin{array}{ccccccccccc}0 & 1 & 2 & 3 & 4 & 5 & 6 & 7 & 8 & 9 & \begin{array}{c}10 \\ \text { Completely }\end{array} \\ \text { Not at all } & & & & & & & & & \end{array}$

How satisfied are you with your friends' support regarding your decision about vaccination?

$$
\begin{array}{ccccccccccc}
0 & 1 & 2 & 3 & 4 & 5 & 6 & 7 & 8 & 9 & 10 \\
\text { Not at all } & & & & & & & & & & \text { Completely }
\end{array}
$$

Do you know the most important benefits and risks associated with the anti-flu vaccination?

$\square$ Yes $\square$ No

Please rate the clarity level of your knowledge on a scale from 0 to 10, where 0 means "not at all (informed)" and 10 "completely (informed)".

$$
\begin{array}{cccccccccccc}
0 & 1 & 2 & 3 & 4 & 5 & 6 & 7 & 8 & 9 & 10 \\
\text { Not at all } & & & & & & & & & & \text { Completely }
\end{array}
$$

How confident are you that your decision is the best for you? Please rate the degree of your confidence on a scale from 0 to 10 , where 0 means "not at all confident" and 10 "completely confident".

$$
\begin{array}{cccccccccccc}
0 & 1 & 2 & 3 & 4 & 5 & 6 & 7 & 8 & 9 & 10 \\
\text { Not at all } & & & & & & & & & & \text { Completely }
\end{array}
$$

Which role should you have in making the decision?

$\square$ Large $\square$ Small $\square$ None at all

During decision-making:

$\square$ I want to share my decision.

$\square$ I want to decide for myself after hearing opinions of others.

$\square$ I want someone else to make the decision for me. 